\title{
Modelling the Impact of Government Policies on Import on Domestic Price of Indian Gold Using ARIMA Intervention Method
}

\author{
Jyothi Unnikrishnan ${ }^{1,2}$ and Kodakanallur Krishnaswamy Suresh ${ }^{3}$ \\ ${ }^{1}$ Research and Development Centre, Bharathiar University, Coimbatore 641046, India \\ ${ }^{2}$ Department of Statistics, Kristu Jayanti College, Bangalore, Karnataka 560077, India \\ ${ }^{3}$ Department of Statistics, Bharathiar University, Coimbatore 641046, India \\ Correspondence should be addressed to Jyothi Unnikrishnan; jyothimanoj@kristujayanti.com
}

Received 29 May 2016; Revised 10 August 2016; Accepted 11 August 2016

Academic Editor: Shey-Huei Sheu

Copyright ( 2016 J. Unnikrishnan and K. K. Suresh. This is an open access article distributed under the Creative Commons Attribution License, which permits unrestricted use, distribution, and reproduction in any medium, provided the original work is properly cited.

\begin{abstract}
The study attempts to determine the impact of government policies of import of gold in India on the domestic price of gold during 2013 using Autoregressive Integrated Moving Average (ARIMA) intervention model. 2013 was an amazing year for Indian gold market where the price had reached its zenith. In April 2013, to curb a record trade deficit, India imposed an import duty of 10 percent on gold and tied imports for domestic consumption to exports, creating scarce supply of the yellow metal and boosting premiums to curtail the Current Account Deficit (CAD). The objective of the paper is to model the impact of this intervention by the government on the domestic price of Indian gold. Suitable ARIMA model is fit on the preintervention period and thereafter the effects of the interventions are analysed. The results indicate that ARIMA $(1,1,1)$ is the most suitable model during preintervention period. Intervention analysis reveals that there is significant decrease in domestic price of gold by $56 \%$ from 2013 . The model may be used by policymakers to analyse the future of gold before framing regulations and policies.
\end{abstract}

\section{Introduction}

Gold has always been an integral part of the socioeconomic ethos of Indian household. Demand for gold is either as bullion for investment or jewellery for gift. India is the second largest importer of gold after China. This is mainly because India limits the use of recycled gold. Import of gold has added to the burden of Indian economy. Import of gold leads to Current Account Deficit as majority of the gold imported is not being monetised. In 2014, Indian household has held more than 22000 tonnes of gold and the gold imported was worth $\$ 34$ billion. If the import of gold has been lower than $\$ 34$ billion, the trade deficit would have been narrower than $\$ 138$ billion [1]. India has formulated various policies since 1947 with different perspectives. 2013 was an important year in the Indian gold market as we witnessed extreme variations in the price of gold. This can be attributed to the changes of import duties which were increased from 2 to 10 percent to impose restrictions in the gold market [2]. The objective of the paper is to model the impact of a government policy introduced in 2013 [3] to reduce its import on the domestic price of gold. ARIMA intervention method is compared with Holt linear trends methods.

\section{Review of Literature}

The concept of intervention analysis was introduced by Box and Tiao [4]. In their article, the model is developed which can find the impact of an intervention and noise on a response variable using difference equation model. The article also discusses the properties of maximum likelihood estimator of parameters and two applications of the model. Chung et al. [5] in their study have modelled the financial crisis in China's manufacturing industry that occurred in 2008. They modelled the impact of the recession that had influenced 
the entire world abruptly. They claim the model to be more precise at explaining and analysing. Ray et al. [6] investigated the effect of introduction of Bt Cotton variety in the year 2002 on the yield of cotton for Gujarat and Maharashtra. This study also concludes that intervention ARIMA model is superior to conventional ARIMA models. Acquah et al. [7] applied intervention ARIMA model to analyse the impact of two different interventions of which one is a step function and the other a pulse function. The objective of the study is to quantify the effects of the review of the timber export levy downwards and the regulation of trade of a wood on the trade policies of wood products in Ghana. Bianchi et al. [8] in their research to find an improved forecasting model for telemarketing centers found that ARIMA intervention model performs better than the simple models such as additive and multiplicative versions of Holt-Winters exponentially weighted moving average models.

\section{Materials and Methods}

3.1. Materials. The daily traded value of gold in Multicommodity Exchange of India (MCX) Limited from March 2011 to March 2016, consisting of 1409 observations obtained from the official website of MCX [9], is used for analysis in the study. The whole set of data is divided into two pre- and postintervention periods. This division is based on ZivotAndrews Unit Root test. 692 observations till 29th June 2013 are considered preintervention period and the remaining 717 observations as postintervention observations.

\subsection{Methodology}

3.2.1. ARIMA Model. The ARIMA $(p, d, q)$ model (8) of a time series refers to the model which is stationary at level with $p$ autoregressive terms and $q$ moving average terms. It may be denoted by

$$
\Phi(B)(1-B)^{d} Y_{t}=\theta(B) \varepsilon_{t},
$$

where

$$
\begin{aligned}
\Phi(B) & \\
= & 1-\Phi_{1} B \\
& \quad-\Phi_{2} B^{2} \cdots \Phi_{p} B^{p} \text { (autoregressive parameter) } \\
\theta(B) & \\
= & 1-\theta_{1} B \\
& \quad-\theta_{2} B^{2} \cdots \theta_{q} B^{q} \text { (moving average parameter). }
\end{aligned}
$$

$\varepsilon_{t}$ - is the noise term and $B$ is the backshift operator. ARIMA model is developed in three steps: model identification, parameter estimation, and diagnostic checking. The correlogram of a stationary series will give us a rough picture of the lags of the model. Parameters are tentatively selected at the identification stage and are estimated by method of iterative least squares. The best model among a few selected tentative models is decided on the basis of the least values of Akaike Information Criterion (AIC) and Bayesian Information Criterion (BIC). AIC and BIC values are computed as follows:

$$
\begin{aligned}
& \mathrm{AIC}=T \log \sigma^{2}+2(p+q+1), \\
& \mathrm{BIC}=T \log \sigma^{2}+2(p+q+1) \log T,
\end{aligned}
$$

where $p$ and $q$ are the parameters of ARIMA model, $\sigma$ is the standard deviation of the model, and $T$ is the number of observations used in estimating the model.

Diagnostic checking does the tests of adequacy of the selected model. This is done by checking if the error terms of the selected model are white noise using Ljung-Box test which has null hypothesis that the noise terms are random and the test statistic $r^{2}$

$$
Q=T(T+2) \sum_{k=1}^{m} \frac{r^{2}}{T-k},
$$

where $T$ is the number of observations used in estimating the model and $m$ is the maximum number of lags.

3.2.2. ARIMA Model with Intervention. The ARIMA model with intervention suggested by Box and Tiao [4] is widely used to analyse the impact of external events on time dependent variables. The methodology of intervention analysis is as follows:

(i) Develop a model for the time series before intervention.

(ii) Add one or more dummy variables that represent the timing of the intervention.

(iii) Reestimate the model, including the new dummy variables for the entire series.

(iv) Interpret the coefficients of the dummy variables as measures of the effect of the intervention.

The intervention model has two components: the noise component which represents the preintervention period and the intervention component that incorporates the effect of the intervention in the model. It may be represented as

$$
Y_{t}=\frac{\omega(B)}{\delta(B)} B_{b} I_{t}+\frac{\theta(B)}{\phi(B)} \varepsilon_{t},
$$

where $Y_{t}$ is the response series, $I$ is the indicator variable coded as a binomial variable with values 0 and 1 to identify the intervention period, $\omega(B)$ is the slope parameter, $\delta(B)$ is the impact parameter, $\phi(B)$ is the autoregressive parameter, $\theta(B)$ is the moving average parameter, and $B$ is the backshift operator.

3.2.3. Holt's Linear Trend Method. This method [10] is adopted to check if a better model can be developed by 

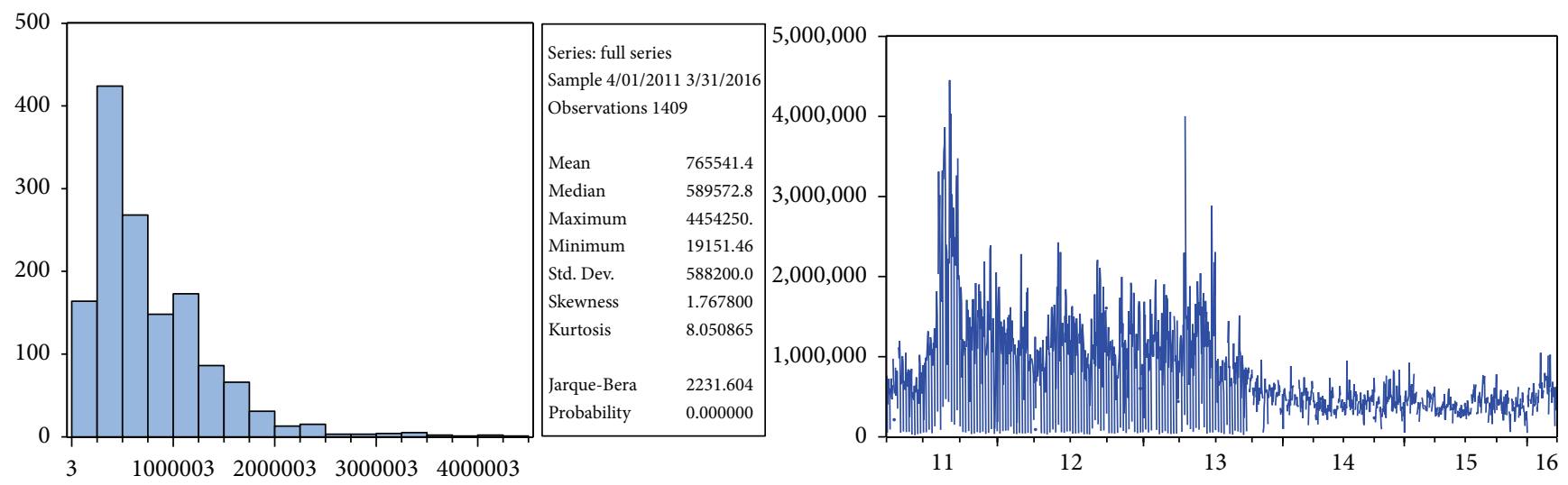

FIgURE 1: Descriptive statistic of the time series from 2011 to 2016.

forecasting with trend. The forecast equation and the two smoothing equations developed are as follows:

$$
\begin{aligned}
& \text { Forecast equation: } Y_{t+h \mid t}=\ell_{t}+h b_{t} \text {, } \\
& \text { Level equation: } \ell_{t}=\alpha y_{t}+(1-\alpha)\left(\ell_{t-1}+b_{t-1}\right), \\
& \text { Trend equation: } b_{t}=\beta^{*}\left(\ell_{t}-\ell_{t-1}\right)+\left(1-\beta^{*}\right) b_{t-1} \text {, }
\end{aligned}
$$

where $\ell_{t}$ denotes an estimate of the level of the series at time $t, b_{t}$ denotes an estimate of the trend (slope) of the series at time $t, \alpha$ is the smoothing parameter for the level, $0 \leq \alpha \leq 1$, and $\beta^{*}$ is the smoothing parameter for the trend, $0 \leq \beta^{*} \leq 1$

3.2.4. Comparing the Model Performance. The forecasting performance of this model can be assessed by the Mean Absolute Percent Error (MAPE) value which is supposed to be minimum. MAPE is defined as

$$
M=\frac{1}{n} \sum_{1}^{n} \frac{A_{t-F_{t}}}{A_{t}},
$$

where $A_{t}$ is the actual value and $F_{t}$ is the forecast value.

\section{Result and Discussion}

The data used for the study has 1409 observations; the descriptive statistics of the data are depicted in Figure 1.

The series has an average of Rs. 765541.40 with standard deviation Rs. 588200.00 and skewness coefficient 1.78 which indicates a drastic fall of price after the first half of 2013. However, the assumption of normality is rejected (JarqueBera $=2231.61$, significance value $=0.00<0.05$ ). To find the exact point of break for the time series to divide the series into two, Zivot-Andrews Unit Root test is used. The result of the test indicates 29th June 2013 is a point of break.

The hypothesised intervention period, 29th June 2013, is considered in the study and it is represented in the graph (Figure 2).

The preintervention period consists of 692 observations and the postintervention period has 717 observations. The descriptive statistics of the price during the two periods are given in Table 1.

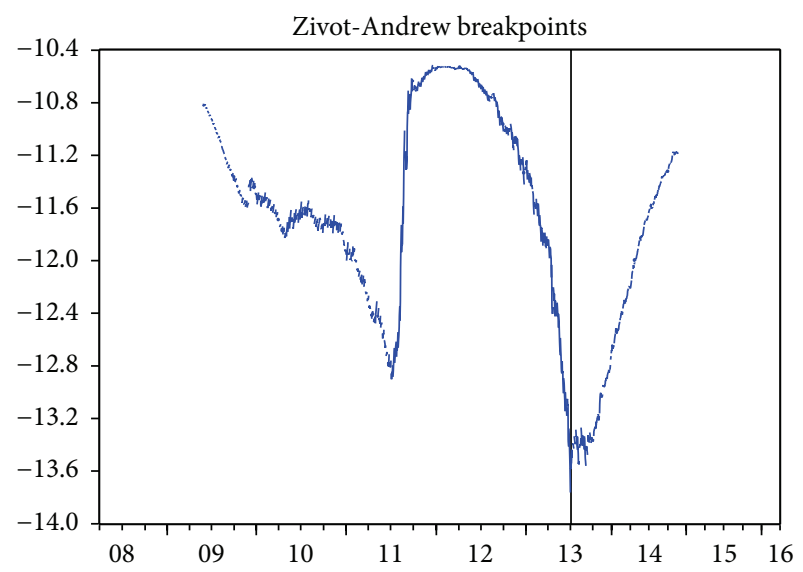

Figure 2: Result of Zivot-Andrews Unit Root test.

It can be observed that the mean price of gold was 1070801 till June 2013 but has depreciated by $56 \%$ to 470925.67 since June 2013. To find the impact of the changes, the $t$-test for means can be used but it will fail to describe the trend of the data; hence, a statistically rigorous method of Intervention Model Analysis is implemented.

As the first step, the most suitable ARIMA model is fitted for the preintervention period. Prior to this, Unit Root Test is carried out to find stationarity of the series. Figure 3 shows the time series as it is and the first differenced series, which indicated stationarity at first difference. This is confirmed by $\mathrm{ADF}$ and KPSS test.

The result of Unit Root Test by Augmented Dickey Fuller (ADF) test and KPSS test is provided in Table 2.

The series attains stationarity at first difference. Now, the correlograms for the autocorrelation function (ACF) and partial autocorrelation function (PACF) are observed to determine the parameters $p$ and $q$ of ARIMA model. The correlogram is given in Figure 4.

The correlogram suggests the value of AR model as 1 and MA also as 1; however, few other possible values are also tested and one model is accepted based on the least values of AIC and BIC. The result of these are provided in Table 3. 

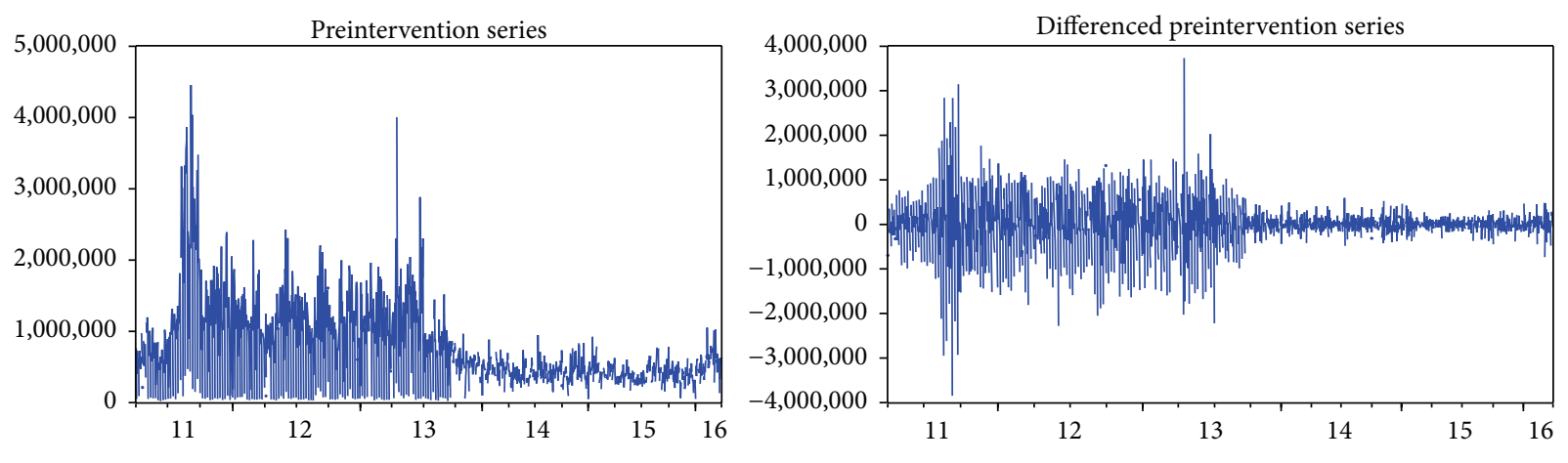

Figure 3: Line graph of the series at level and first difference.

TABLE 1: Descriptive statistics of the two time periods under study.

\begin{tabular}{lcccc}
\hline Period & $N$ & Mean & SD & Skewness \\
\hline 1st April 2011-29th June 2013 & 692 & 1070801.00 & 693745.70 & 0.95 \\
29th June 2013-31st March 2016 & 717 & 470925.67 & 7366.05 & 0.99 \\
\hline
\end{tabular}

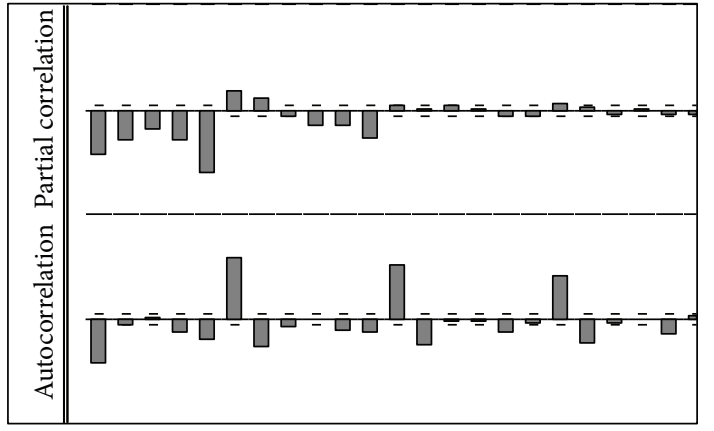

FIGURE 4: Correlogram of the preintervention series.

ARIMA $(1,1,1)$ is considered as the best model since it corresponds to the least values of AIC and BIC. The model developed is represented as

$$
Y_{t}=0.9829 Y_{(t-1)}-\varepsilon_{t}-0.8608 \varepsilon_{(t-1)} .
$$

The MAPE of this model is 103.4 and RMSE is 585.3. The $t$-test for significance of the coefficients also accepts the coefficients as significant.

4.1. ARIMA Intervention Model. The complete series is used for developing intervention ARIMA model. The developed model is provided in Table 4.

The developed model is considered for forecast.

4.2. Diagnostic Checking. Residual analysis of the model is carried out; the result is displayed in Figures 5 and 6.

The adequacy of the model is validated using Ljung-Box test for randomness and Shapiro-Wilk's test for normality of the residuals of the model. The $p$ value of Ljung-Box test for randomness is 0.5493 , accepting the null hypothesis of randomness. Similarly, the null hypothesis of normality of

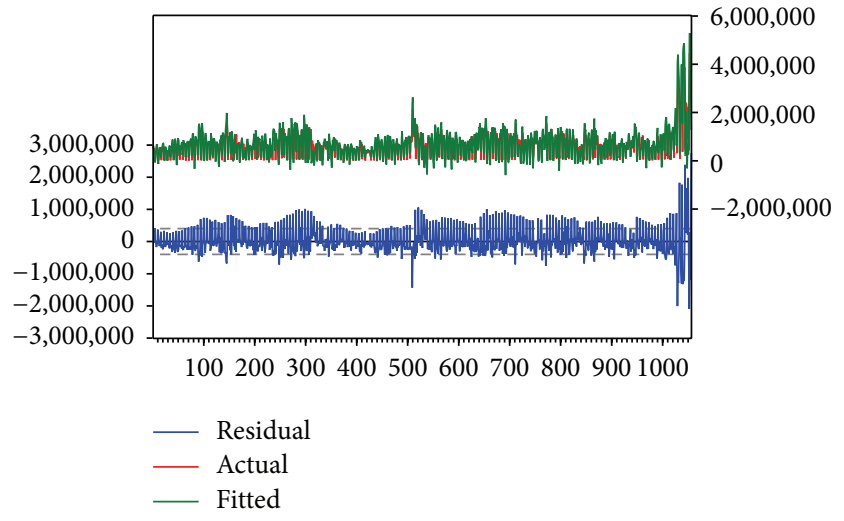

Figure 5: Actual and fitted model.

the residuals by Jarque-Bera test is also accepted ( $p$ value $=$ 0.002).

4.3. Holt's Linear Trend Method. This method is adopted to check if a better model can be developed by forecasting with trend. The forecast equation and the two smoothing equations developed are presented in Table 5.

The MAPE values are compared to find a better model. The MAPE value of ARIMA intervention model is 103.4 while that of Holt's linear trend model is 195.67 . Hence, it can be concluded that the ARIMA intervention model is better than Holt's linear trend method.

\section{Conclusion}

The study identified the significance and impact of the government policy on import of gold which was put forth in May 2013 by employing ARIMA intervention analysis. The findings suggest that the impact of the policy can be best portrayed by this method. The value of impact is found to be Rs. 167550.7 with a slope Rs. 5.78. This method is 
TABLE 2: Result of Unit Root test of preintervention period.

\begin{tabular}{lccr}
\hline & & \multicolumn{2}{c}{ Tests of stationarity of the series } \\
Test & Null hypothesis & At level & At first difference \\
\hline ADF & Series is not stationary & $-1.8015(0.3800)$ & $-22.449^{* *}(0.000)$ \\
KPSS & Series is stationary & $0.1147\left(0.739^{\#}\right)$ & $0.0173^{* *}\left(0.739^{\#}\right)$ \\
\hline
\end{tabular}

** Indicates significance at $1 \%$ level. ${ }^{*}$ Indicates critical value below which is the acceptance region of the null hypothesis.

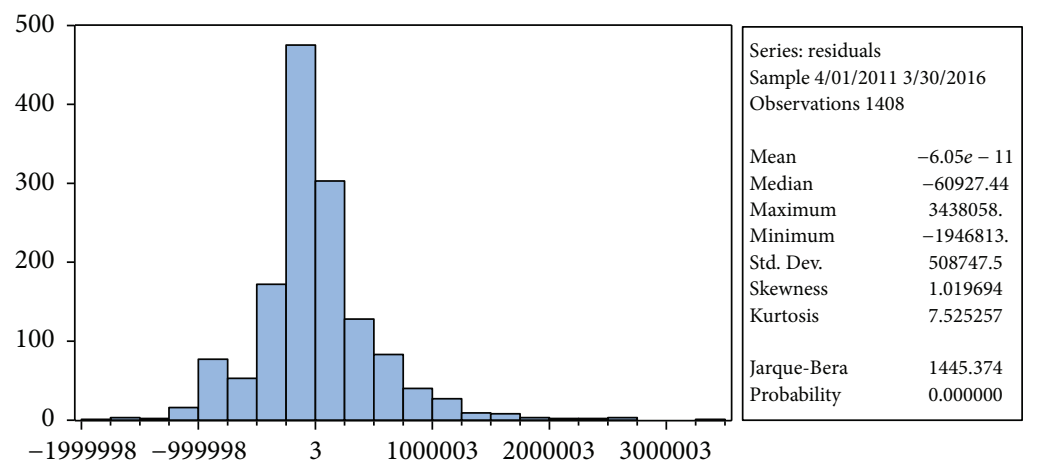

FIGURE 6: Histogram of residuals after fitting intervention ARIMA model.

TABLE 3: Comparison of AIC and BIC values.

\begin{tabular}{lccc}
\hline$P$ & $Q$ & AIC & BIC \\
\hline 2 & 1 & 29.203 & 29.211 \\
1 & 1 & 28.729 & 28.739 \\
0 & 1 & 29.763 & 29.767 \\
0 & 2 & 29.631 & 29.635 \\
\hline
\end{tabular}

TABLE 4: Intervention ARIMA model parameter estimation.

\begin{tabular}{lcccc}
\hline Variable & Coefficient & Std. error & $t$-statistic & Prob. \\
\hline General mean $(\mu)$ & 16927.47 & 6018.846 & 2.812411 & 0.0050 \\
Impact $(\omega)$ & 167550.7 & 2266.929 & 73.91087 & 0.0000 \\
Slope $\delta$ & 5.78 & 1.4817 & 2.1715 & 0.0360 \\
AR(1) coefficient & 0.982926 & 0.005431 & 180.9707 & 0.0000 \\
MA(1) coefficient & -0.860864 & 0.013603 & -63.28570 & 0.0000 \\
\hline$R$-squared & & 0.421113 & \\
Adjusted $R$-squared & & 0.419876 & \\
SE of regression & & 448148.4 & \\
Sum squared resid. & & $2.82 E+14$ & \\
Log-likelihood & & -20318.00 & \\
Durbin-Watson stat. & & 1.880985 & \\
Mean dependent var. & & 765683.2 & \\
SD dependent var. & & 588384.9 & \\
Akaike info. criterion & & 28.86647 & \\
Schwarz criterion & 28.88139 & \\
Hannan-Quinn criter. & & 28.87205 & \\
\hline
\end{tabular}

1 stands for the order of AR and MA.

better than the $t$-test for difference of means before and after the interventions. The model is compared with Holt's linear trend method and it was found that ARIMA intervention is
TABLE 5: Holt's linear trend model.

\begin{tabular}{lc}
\hline \multicolumn{2}{c}{ Parameters } \\
\hline Alpha & 0.994155 \\
Beta & $5.77 E-05$ \\
Gamma & 0.000114 \\
\hline \multicolumn{2}{c}{ Initial parameters } \\
\hline Initial level & 1533.309 \\
Initial trend & 0.012347 \\
Initial state 1 & 1.000455 \\
Initial state 2 & 1.000410 \\
Initial state 3 & 0.999819 \\
Initial state 4 & 0.999497 \\
Initial state 5 & 0.999614 \\
Initial state 6 & 1.000205 \\
\hline Compact log-likelihood & -8509.727 \\
Log-likelihood & -5578.774 \\
Akaike Information Criterion & 17039.45 \\
Schwarz criterion & 17091.48 \\
Hannan-Quinn criterion & 17058.94 \\
Sum of squared residuals & 0.168186 \\
Root mean squared error & 0.011191 \\
Average mean squared error & 519.3459 \\
\hline
\end{tabular}

better. This study also informs policy makers of the impact of decisions and suggests the average value and slope of the impact.

\section{Competing Interests}

The authors declare that they have no competing interests. 


\section{References}

[1] http://www.gold.org/supply-and-demand/gold-demand-trends/ back-issues/gold-demand-trends-full-year-2014.

[2] https://www.rbi.org.in/Scripts/NotificationUser.aspx.

[3] N. E. Emmanuel, "Indian gold policies and reforms and it's impact on imports and consumption," Asia Pacific Journal of Research, vol. 1, no. 36, pp. 76-81, 2016.

[4] G. E. P. Box and G. C. Tiao, "Intervention analysis with applications to economic and environmental problems," Journal of the American Statistical Association, vol. 70, no. 349, pp. 7079, 1975.

[5] R. C. P. Chung, W. H. Ip, and S. L. Chan, "An ARIMAintervention analysis model for the financial crisis in China's manufacturing industry," International Journal of Engineering Business Management, vol. 1, no. 1, pp. 15-18, 2009.

[6] M. Ray, V. Ramasubramanian, A. Kumar, and A. Rai, "Application of time series intervention modelling for modelling and forcasting cotton yield," Statistics and Applications, vol. 12, no. 1-2, pp. 61-70, 2014.

[7] S. B. Acquah, R. K. Avuglah, and E. Harris, "Impact of trade policies on wood products export in Ghana," American Journal of Mathematics and Statistics, vol. 5, no. 5, pp. 221-229, 2015.

[8] L. Bianchi, J. Jarrett, and R. C. Hanumara, "Improving forecasting for telemarketing centers by ARIMA modeling with intervention," International Journal of Forecasting, vol. 14, no. 4, pp. 497-504, 1998.

[9] https://www.mcxindia.com/market-data/historical-data.

[10] D. Gujarati, D. C. Porter, and S. Gunasekhar, Basic Econometrics, McGraw Hills Companies Publishers, 5th edition, 2012. 


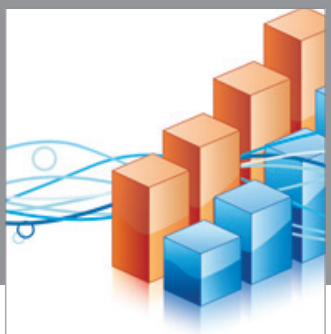

Advances in

Operations Research

vatem alat4

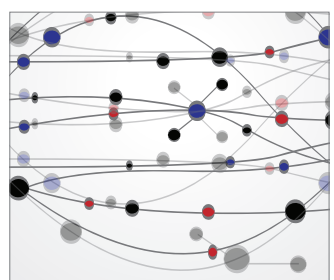

\section{The Scientific} World Journal
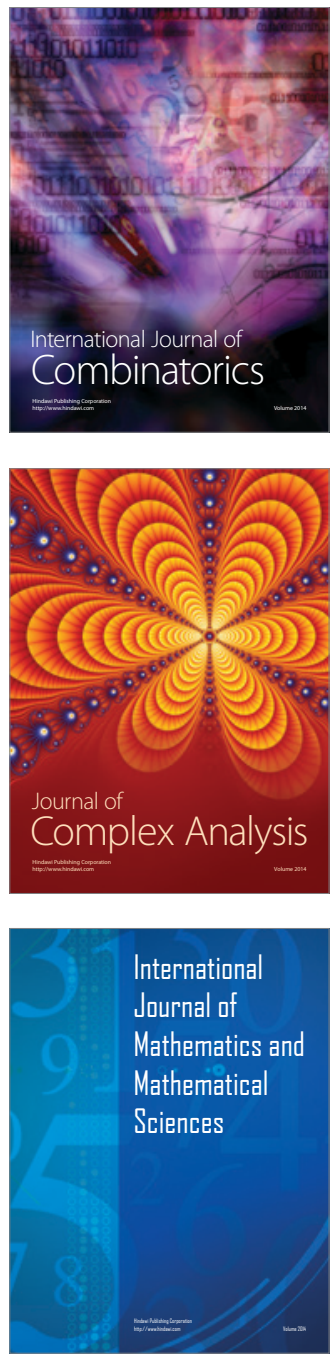
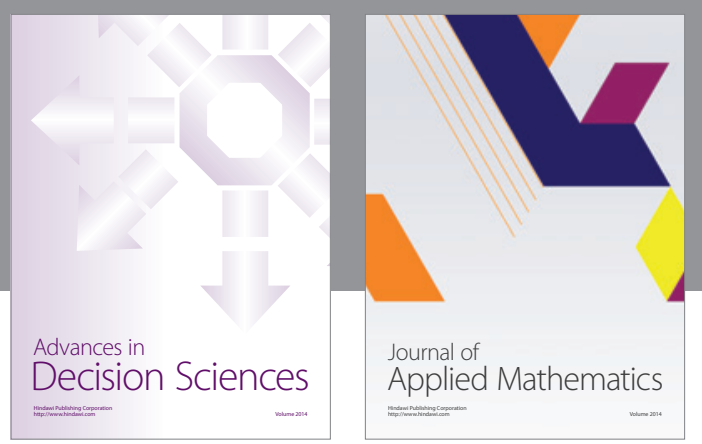

Algebra

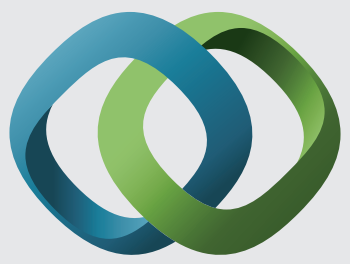

\section{Hindawi}

Submit your manuscripts at

http://www.hindawi.com
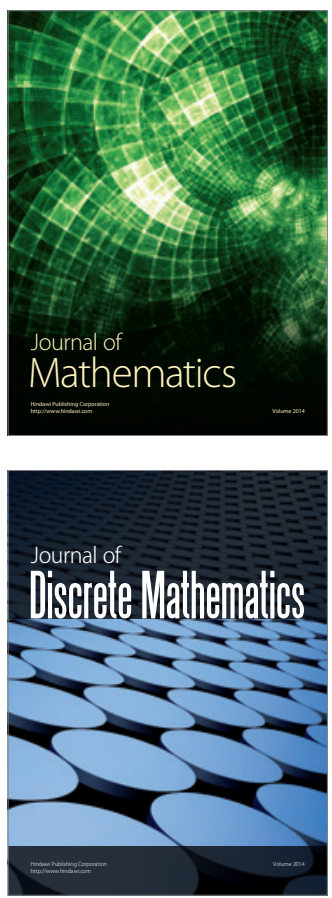

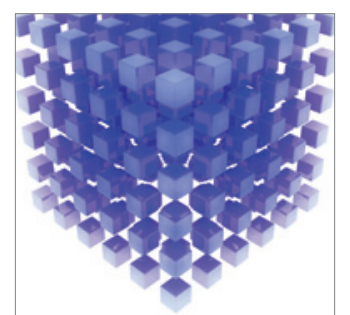

Mathematical Problems in Engineering
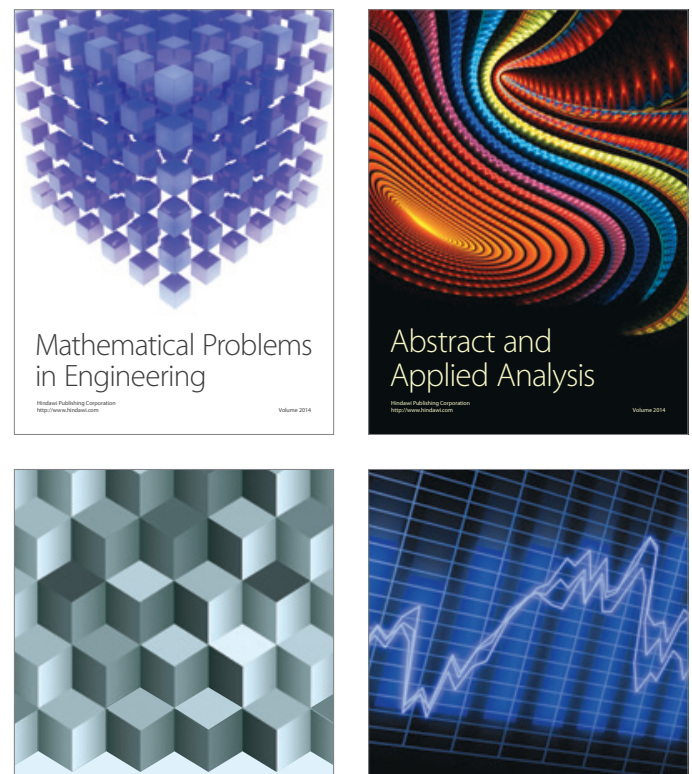

Journal of

Function Spaces

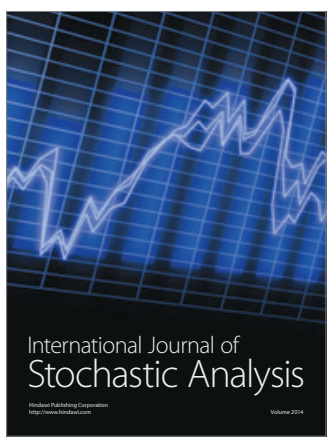

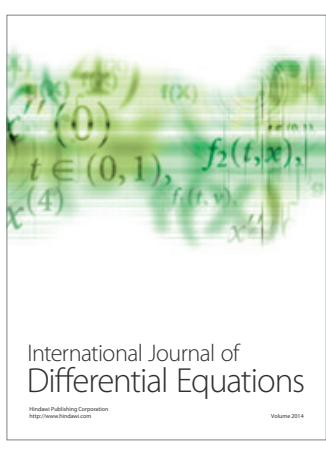
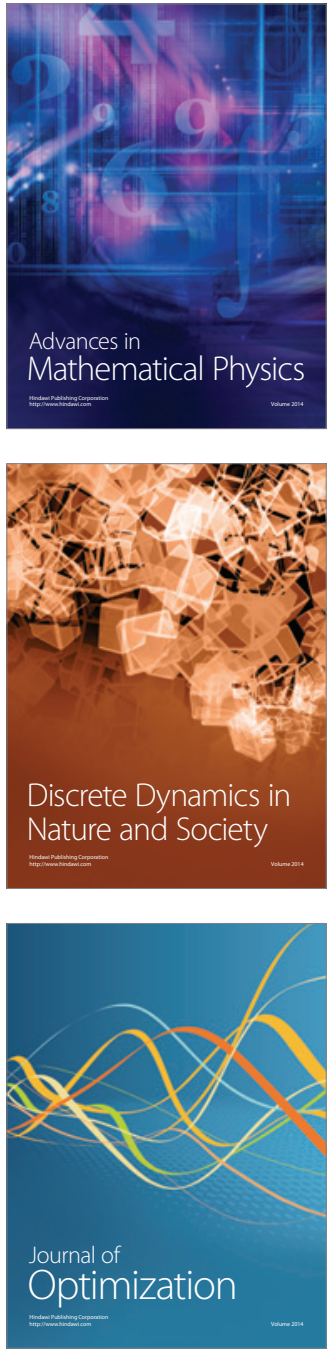